Daniel Malva, Clayton Policarpo, Agda Carvalho, Edilson Ferri, Miguel Alonso, Sergio José Venancio Júnior *

\title{
Janelas Afetivas: espaços de compartilhamento
}

Daniel Malva é Mestre pelo PPG em Artes do IA - Unesp, São Paulo. Membro do grupo de pesquisa cAt - ciência/ARTE/ tecnologia e do GIIP - Grupo Internacional e Interinstitucional de Pesquisa em Convergências entre Arte, Ciência e Tecnologia (IA-Unesp).<info@malva.fot.br> ORCID: 0000-0002-6301-2813

Clayton Policarpo é Doutorando (bolsa Capes) e mestre em Tecnologias da Inteligência e Design Digital (TIDD), PUC-SP. integrante dos grupos de pesquisa TransobjetO (TIDD - PUC-SP) e Realidades (ECA - USP).

<clayton.policarpo@gmail.com>

ORCID: 0000-0003-3097-5282

Agda Carvalho é Artista Visual e Curadora. Pós Doutorado em Artes (IA / Unesp) e Humanidades Digitais (MediaLab/UFG). Doutora em Ciências da Comunicação (ECA-USP). Mestre em Artes Visuais (IA /UNESP). Membro do GIIP: Grupo Internacional e Interinstitucional de Pesquisa em Convergências entre Arte, Ciência e Tecnologia (IA/UNESP). Docente e pesquisadora do Instituto Mauá de Tecnologia.<agdarcarvalho@gmail.com> ORCID: 0000-0002-3604-2750
Resumo Este texto aborda as novas realidades pessoais e profissionais que o isolamento social trouxe, considerando a proposta artística Janelas Afetivas (2020) elaborada pelo coletivo COM.6, que propõe um diálogo entre distintas experiências de compartilhamento de mundo. Esta reflexão questiona a intensificação dos diversos encontros realizados por softwares de videoconferência, ao abordar as relações de encontros por meio de janelas remotas e as interrelações entre os mundos íntimos com suas nuances e situações reveladas pelas constantes conexões e exposições de imagem no cotidiano. As variadas rotinas e as mudanças com o confinamento disparam múltiplos comportamentos diante de telas e dispositivos diversos, e é nesta situação que as janelas são ressignificadas com novas percepções e entendimentos de mundo. O nosso espaço é o mesmo, mas o tempo é outro, já que o dia não é mais linear e as atividades aparentemente se repetem.

Palavras chave Performance, Audiovisual, Pandemia, Videoconferência, Privacidade. 


\section{Affective Windows: spaces of sharing}

Edilson Ferri é Artista e Arquiteto. Doutorando em Artes (IA/UNESP). Mestre em Poéticas Visuais (UNICAMP). Docente da Faculdade Impacta Tecnologia (SP). Membro do GIIP: Grupo Internacional e Interinstitucional de Pesquisa em Convergências entre Arte, Ciência e Tecnologia (IA/UNESP). <edilsonferri@gmail.com> ORCID: 0000-0001-9611-7067

Miguel Alonso é Artista plástico e arte educador, doutorando pelo PPGAV - ECA/ USP. Mestre pelo PPG em Artes da UNESP. Educador de Tecnologias e Artes no SESC - São Paulo. Formado em bacharelado e em licenciatura em Artes Visuais na UNESP. Membro dos Grupos de Pesquisa Realidades (ECA - USP) e GIIP (IA/UNESP).

<miguelalonso@usp.br>

ORCID: 0000-0003-0829-5192

Sergio José Venancio Júnior é Doutorando em Poéticas Visuais (ECA USP), bolsista CAPES PROEX. Mestre em Artes Visuais (ECA USP). Membro do Grupo de Pesquisa Realidades (ECA USP). Docente do Curso de Especialização em Design Gráfico do Instituto de Artes Unicamp e da Pós-Graduação em Arquitetura Digital e Projetos Paramétricos do Centro Universitário Belas Artes SP. <svenancio@usp.br> ORCID: 0000-0003-4635-0033
Abstract This text addresses the new personal and professional realities that social isolation has brought, considering the artistic proposal Janelas Afetivas (Affective Windows - 2020), elaborated by COM.6 collective, which proposes a dialogue between different experiences of sharing. We question the intensification of meetings carried out by video conferencing software, taking into account the established relationships in these remote windows, as well as the interrelations between intimate worlds, each with their nuances and situations revealed by the constant connections and image exhibitions. The different routines and changes in confinement trigger multiple behaviors in front of screens and devices. In this situation, windows have different meanings with new perceptions and understandings of the world. Our space is the same, but our time has changed, since a day is no longer linear, and all activities apparently repeat themselves.

Keywords Performance, Video, Videoconference, Pandemic, Privacy.

\section{Ventanas afectivas: espacios para compartir}

Resumen Este texto aborda las nuevas realidades personales y profesionales que ha traído el aislamiento social, considerando la propuesta artística Janelas Afetivas (Ventanas Afectivas - 2020), elaborada por el colectivo COM.6, que propone un diálogo entre diferentes experiencias de compartir. Esta reflexión cuestiona la intensificación de los encuentros realizados mediante software de videoconferencia. Tenemos en cuenta las relaciones establecidas por estas ventanas a distancia, así como las interrelaciones entre mundos íntimos, cada uno con sus matices y situaciones reveladas por las constantes conexiones y exposiciones de imágenes. Las diferentes rutinas y los cambios de encierro desencadenan muchos comportamientos frente a las pantallas y dispositivos. En esta situación, las ventanas se resignifican con nuevas percepciones y comprensiones del mundo. Nuestro espacio es el mismo, pero nuestro tiempo ha cambiado, porque un día ya no es lineal, $y$ todas las actividades se repiten aparentemente.

Palabras clave Performance, Vídeo, Videoconferencia, Pandemia, Privacidad. 


\section{Introdução}

O projeto Janelas Afetivas, de autoria do coletivo COM.6, emerge como uma reflexão em processo sobre o atual cenário marcado pela migração de ocupações cotidianas para espaços digitais, desencadeada pela pandemia do SARS-COV2, em 2020. Em uma tentativa de formular uma leitura poética da experiência de uma reconfiguração de hábitos e rotinas mediadas por computadores e telas, o trabalho reúne os integrantes do COM.6 em uma transmissão em tempo real, onde gestos performativos são transmutados em sons, texturas e sobreposições gráficas, de modo a estabelecer diálogos não-verbais entre os diferentes agentes que compõem a ação. No intuito de contextualizar a proposta e alçar uma compreensão ampla acerca do impacto ocasionado pela consolidação de ferramentas de comunicação no cotidiano, o presente texto propõe realizar um breve retrospecto das relações entre seres humanos, tecnologia e lugar vivido. Buscamos entender os reflexos de uma dissolução das fronteiras entre público e privado, a partir da leitura de alguns artistas que utilizam linguagens tecnológicas em seu processo de criação e que dialogam com estas questões.

$\mathrm{O}$ texto também explora um mecanismo que permite a prática de poéticas visuais baseadas em tecnologias audiovisuais em rede. Tais recursos oferecem possibilidades de exploração de diálogos corporais e visuais de forma remota, por meio de plataformas de videoconferência. Estes diálogos são captados, modificados e transmitidos por meio de um software de edição ao vivo e um site de exibição em sistema streaming. Deste modo, enfatizamos o atravessamento da tecnologia nos modos de vida e a ressonância da diversidade de produções artísticas que atualmente vivenciam o entrecruzamento do espaço físico e remoto, bem como a intensificação de processos colaborativos que estão compartilhados na rede.

\section{Preâmbulo para a ação em rede}

No primeiro semestre de 2020 , em virtude da urgência sanitária ocasionada pela propagação do coronavírus, os serviços tidos como não essenciais - comércios, restaurantes, escolas etc. - tiveram suas atividades presenciais interrompidas, sendo forçados a operar de maneira remota. Tais lugares configuram atividades sociais que formaram, ao longo do século passado, nossa relação com o que consideramos cotidiano. 0 uso das tecnologias passa a moldar, de maneira radical, nossos hábitos de sociabilização e as diferentes maneiras que dispomos para experienciar a paisagem das cidades. 
Condicionada na modernidade à noção de encontro físico nos espaços públicos das cidades, a concepção de experiência corporalizada faz convergir outros vetores e endereçar expectativas de natureza diversa no contexto atual, em que as ações e as comunicações se realizam crescentemente em ambientes virtuais, mediadas por telas e interfaces informacionais (Fatorelli, 2013, p.101).

Embora não se possa negar que existam contrastes econômicos e sociais no acesso a equipamentos e serviços de conexão, o atual panorama tecnológico permite que atividades de trabalho, estudo, lazer sejam mediadas por telas e dispositivos. Adicionalmente, trazem novas responsabilidades e ampliam os campos de discussões que dizem respeito às relações humanas.

Ao tempo que percebemos uma confluência de rotinas para um mesmo suporte, rompem-se as barreiras, antes já desgastadas, entre o público e o privado e entre o profissional e o pessoal. A não separação entre os espaços que contemplam as diversas atividades que realizamos, configuram o tempo da vida enquanto uma continuidade das obrigações de trabalho e lazer. Como pontuado por Marcus Bastos (2020), temos a impressão "que as atividades feitas fora de casa funcionam como uma espécie de baliza que organiza o relógio das pessoas, e ficar em casa resulta numa situação em que aos poucos não fica mais tão clara a diferença entre a manhã, a tarde, a noite, o dentro e o fora." (ibid., p. 11). Esta situação de espaços múltiplos e simultâneos, a indeterminação do tempo, que agora é flexível, e a potencialização da vivência do compartilhamento remoto são questionamentos que fundamentam a ação performática online Janelas Afetivas, já que a tecnologia reverbera no meio em que se insere, ao tempo em que desencadeia novos hábitos e rotinas no sujeito.

Observa-se que, com o rádio, a televisão e o telefone, o mundo à nossa volta adquiriu uma leitura não linear, o que tornou natural a absorção de novas linguagens advindas da rede (Di Felice, 2009, p. 150). 0 debate acerca do impacto da eclosão de tecnologias em rede permeou pesquisas nas áreas de desenvolvimento, comunicação, humanidades e artes. Com a evolução dos meios de comunicação e a ampla disseminação de dispositivos móveis, as distinções entre físico e virtual cedem espaço para uma inextricável mescla de experiências mediadas por ferramentas digitais. As dificuldades de acesso à rede, antes impostas pelas limitações de tecnologias e infraestruturas, são dissipadas para um modelo de conexão e disponibilidade ininterruptas. Com a popularização dos smartphones, tablets e computação pervasiva - dispositivos que, em sua discrição, permanecem invisíveis aos usuários, ao tempo que são capazes de configurar ações nas cidades - a tecnologia passa a operar inerente à própria urbe. Neste contexto, irrompem as delimitações dualistas entre espaço digital e físico, entre o presencial e o virtual, e geram-se campos de intersecção que recebem nomes como espaço intersticial (Santaella, 2010), território informacional (Lemos, 2011) e espaço cíbrido (Beiguelman, 2004). 
O chamado "novo normal" é parte de um percurso que se inicia já nos primórdios da difusão de computadores pessoais e serviços em rede. Com a digitalização da vida, e uma série de novos métodos e procedimentos, é instaurado um regime de disponibilidade constante. Frente aos impactos da crise sanitária do coronavírus são exigidas reações rápidas e a mobilização de múltiplos setores da sociedade. A imposição de novas dinâmicas para o trabalho remoto, a ampla digitalização de serviços - potencializadas pelas restrições de circulação no período (PWC BRASIL, 2020) -, o uso de dispositivos para monitorar e rastrear os pacientes infectados pelo COVID-19 são algumas das práticas mediadas por tecnologias que, ao serem adotadas como tentativa de conter os impactos ocasionados pela pandemia, também incitam debates quanto aos limites de privacidade e vigilância em uma sociedade hiperconectada. A nossa casa passa a figurar como cenário para a transmissão de aulas, reuniões de trabalho, programas de TV, telejornais. As oscilações do serviço de internet, os vídeos em baixa resolução e a pouca formalidade dos ambientes domésticos repercutem situações inusitadas que contrastam com a formalidade que é comumente exigida nos espaços de trabalho. Desse modo observa-se uma dissolução peremptória do limiar entre "público" e "privado", ao tempo que emergem reflexões sobre o tema, provindas de diferentes campos do conhecimento.

\section{0 apagamento das fronteiras entre público e privado: experimentações nas artes}

Nas últimas décadas, diversos artistas têm se empenhado em desenvolver proposições estéticas que se propõem em desvelar novas camadas da tecnologia, por vezes não idealizadas em sua concepção e consolidação. A onipresença das redes que passam a abarcar os diversos aspectos da vida, ao ponto de embaralhar as definições de intimidade, são com frequência abordadas em obras que utilizam as linguagens tecnológicas em seus processos de criação e difusão.

A dissipação entre fronteiras de "público" e "privado", a partir do uso da tecnologia, remonta a algumas das práticas precursoras da arte da performance. $O$ registro do ambiente particular com o uso de aparatos audiovisuais passa a ser um recurso comum na produção em arte, de forma a configurar a estrutura de composição dos trabalhos artísticos. Entre os anos 1960 e 1970, diversos artistas buscaram explorar o potencial performativo da câmera de vídeo, no registro de ações centradas no próprio corpo e em sua interação com um espaço imediato do ateliê. Os trabalhos realizados pelos artistas precursores da videoperformance concentravam-se na potência indicial da ferramenta. Eram comuns peças que registravam ações cotidianas encenadas em espaços privativos, "o conjunto técnico de câmera e monitor tornou-se instrumento para gravar e revelar ações privadas dentro do estúdio dos artistas que não eram necessariamente designadas para 
serem exibidas ao público" (Salter, 2010, p.123). As câmeras e monitores nas performances agem como um novo espelho que exibe um rosto e um corpo transformados, reduzindo ou avançando a velocidade, acelerando ou retrocedendo no tempo (ibid.).

Em Walking in an Exaggerated Manner Around the Perimeter of a Square, de 1968, Bruce Nauman caminha colocando um pé frente ao outro com um movimento pronunciado de seus quadris, seguindo o perímetro de um quadrado desenhado com fita adesiva no piso de concreto de sua sala. Com duração de dez minutos, o vídeo capta a ação de Nauman a partir de um ponto fixo e, a despeito de sua aparente simplicidade, incita uma ruptura com convenções do cinema, televisão e arte.

No Brasil, uma das obras considerada precursora na videoarte é Marca Registrada, de 1975, realizada por Letícia Parente. A artista, munida de uma câmera, registra o ato de "bordar" na sola do pé as palavras “MADE IN BRAZIL". Na leitura de André Parente (2014), a obra da artista "é marcada pela ideia de extrair do corpo uma imagem que nos dê razão para acreditar no mundo em que vivemos. Os vídeos dessa artista são, cada um deles, preparações e tarefas por meio das quais o corpo revela os modelos de subjetividade que o aprisionam" (ibid.). A performance, executada sem uma audiência específica, atribui à documentação o status de obra. Gravado em um plano sequência em um espaço doméstico, Marca Registrada faz uma analogia a uma ocupação tradicionalmente feminina, o ato de bordar, ao tempo que "revela o processo de coisificação do indivíduo" (ibid.).

Entre os anos 1980 e 1990, Sadie Benning desenvolve o trabalho If every girl had a diary, a partir de vídeo-diários produzidos durante o período em que estava no colégio. Em uma série de registros a jovem estabelece uma interlocução com sua câmera de brinquedo Fisher-Price, onde revela suas inseguranças e conflitos em um processo de construção de personalidade. Ao assistir os relatos de Benning somos tragados por um campo de visão íntimo, com imagens em close e por vezes completamente ininteligíveis, que pressagiam as redes sociais de compartilhamento de vídeos como o YouTube e, mais recentemente, o TikTok.

Com as tecnologias em rede e a proliferação de páginas pessoais, blogs e redes de sociabilização, é promovida uma cultura de compartilhamento e de narrativas em primeira pessoa, o que faz com que os limites entre público e privado se tornem ainda mais tênues. Enquanto a mídia de massa se conformou como um meio unidirecional de transmissão, onde a influência do espectador pouco interferia no formato dos conteúdos produzidos pelas emissoras de rádio e televisão, com a web é apresentada a possibilidade dos usuários se colocarem como criadores em potencial. Munidos de equipamentos capazes de produzir, armazenar e compartilhar conteúdos em diferentes linguagens, o sujeito do século XXI permanece em hiperconexão e em um estado de alerta constante. 
Com as facilidades oferecidas pela integração de câmeras aos dispositivos móveis, que também dispõem de acesso à internet, uma infinidade de proposições estéticas passa a utilizar a rede como vitrine e promovem uma revisão dos modelos institucionalizados de exibição. Uma das marcas de nossa época é a cultura de captura e compartilhamento de imagens de si. Contas de Instagram reúnem projetos biográficos, hedonistas e críticos, em uma profusão de narrativas. (Policarpo, 2020).

Estas possibilidades abriram precedentes de discussões e produções na arte, em que artistas se apropriam destas ferramentas e utilizam sua causalidade como uma linguagem crítica ou para compartilhar suas posições perante assuntos contemporâneos. Enxerga-se que essas novas maneiras comportamentais extrapolam as transformações ambientais e contaminam o comportamento ao criar, para estes novos ambientes, possibilidades de múltiplas existências.

O rompimento com uma suposta privacidade e os mecanismos de vigilância da tecnologia estão presentes na obra Casa Aberta, 2009, de Claudio Bueno. Apresentado em diferentes ocasiões, o trabalho se configura como uma instalação onde o visitante pode assistir uma transmissão de vídeo realizada a partir da residência e do ateliê do artista. Além da situação absolutamente trivial que o projeto oferece ao evidenciar o "aspecto ordinário e desinteressante da vida cotidiana" (Bueno, 2009), o público também pode interferir na rotina do espaço privado: com uma chamada de celular é possível ligar, desligar ou trocar os canais da televisão que integra o enquadramento voyeurístico. Em texto curatorial da exposição "Demasiada Presença", 2009, na Escola São Paulo, Christine Mello coloca que as experimentações em arte e tecnologia propiciam uma ampliação da noção de presença e, com isso, apontam para uma nova dimensão.

Traz-nos a dimensão de um espaço conectado a temporalidades simultâneas, cuja natureza presencial é transitória, híbrida, entre a presença física e a virtual, entre o lugar fixo e o móvel. Acentuam processos de interação entre diferentes espaços. As experiências da arte nesse contexto promovem ações em espaços fluídos e intensificam o desejo de presença, de tomar contato. Seus sentidos associam a vontade de estar conectado à coexistência da esfera pública-privada. (Mello, 2009, n.p.)

Em 2010, Eva e Franco Mattes propõem explorar uma suposta banalização e perversidade instituída nas relações de exibicionismo e compartilhamento, presentes no cerne da web 2.0. Em No Fun, os artistas mostram o registro em vídeo da reação de um público involuntário a uma cena de suicídio, encenada no ambiente de bate-papo por vídeo Chatroulette. A plataforma oferece um emparelhamento aleatório entre os seus usuários, no 
intuito de forçar uma sociabilização e incitar a vicissitudes de impulsos de voyeurismo e exibicionismo, onde permanecemos em um estado de contemplação ou de reafirmação de um ego narcísico. Ao serem defrontados com uma ação inusitada, como o suicídio teatral de Mattes, os usuários expressam pânico, desprezo, indiferença e mesmo se excitam com a situação.

Esta experiência de onipresença da tecnologia, atravessa uma diversidade de atividades artísticas, inserida nas intimidades cotidianas, dialoga com a proliferação de informações e está conectada com o mundo ao redor. É uma situação que nos aproxima dos acontecimentos e fenômenos públicos, e de certa forma, mistura o que é público e privado.

\section{Processo e poética do projeto Janelas Afetivas}

O coletivo COM. 6 é criado em 2017, com o encontro de artistas-pesquisadores interessados em trabalhar questões acerca do corpo e corporalidades possíveis mediadas pelo ambiente digital. Algumas das principais questões que tangenciam as pesquisas e interesses comuns dos integrantes passam a compor a sigla que nomeia o grupo - Corporalidade, Oralidade e Matéria $=$ COM.6. Desde então o grupo se reúne e produz obras artísticas e textos acadêmicos. Em virtude da dificuldade em conciliar a agenda de compromissos dos integrantes, que desenvolvem outras atividades profissionais e acadêmicas, a maioria dos encontros do coletivo, desde sua origem, tem acontecido de modo remoto. Dessa forma, podemos dizer que o processo de criação em ambientes online de compartilhamento, que passa a ser exigido em um contexto pandêmico, já figurava em boa parte do processo de criação e desenvolvimento de projetos do coletivo. As dinâmicas de trabalho remoto e as reflexões incitadas pelos embates entre distância e proximidade estão no cerne da produção do grupo.

Janelas Afetivas surge como uma proposta de reapropriação de tecnologias em rede para realização de experimentações audiovisuais em tempo real que, ao tempo que proporcionam diálogos não-verbais entre os integrantes do coletivo COM.6, são transmitidas ao vivo para o público via YouTube. Partimos da observação da confluência de rotinas diárias para as telas dos dispositivos, em plataformas de videoconferência (Google Meet, Microsoft Teams, Zoom) que ordenam os participantes em uma disposição de pequenas "janelas". Tais interfaces lembram tabuleiros - nelas vemos os nomes dos participantes, seus rostos e os cenários de suas intimidades e instauram um novo paradigma de sociabilização para o ano de 2020. Em um exercício de desconstrução dos limites rígidos desse enquadramento imposto reside o projeto Janelas Afetivas. 
O mundo da simulação transforma o computador em um laboratório para
a construção de ensaio de identidades múltiplas, mas integradas, cuja fle-
xibilidade, reversibilidade e satisfação se apoiam em ter acesso à vontade
a muitas personalidades diferentes (Fontcuberta, 2012, p. 183)

Em formato de apresentações online, até então realizadas com duração entre 5 e 13 minutos, os integrantes do coletivo realizam microperformances e ações de caráter performativo que correspondem ao repertório particular de práticas diárias e intenções de cada artista. Ainda que o improviso e o acaso sejam desejáveis na realização das "sessões" do trabalho, cada apresentação é composta por uma sequência de procedimentos: 1) um encontro prévio entre os integrantes do COM.6, para definição de temas que irão estimular e disparar as ações individuais na apresentação; 2) desenvolvimento da composição sonora que guiará a apresentação, elaborada com antecedência a partir de ruídos cotidianos e mixada por Daniel Malva; 3) encontro/atuação, momento no qual os artistas realizam e transmitem suas ações individuais em um grupo fechado, através de uma plataforma de videoconferência; 4) manipulação digital em tempo real das imagens enviadas pelos performers e transmissão para o público via YouTube, com o auxílio do software de código aberto OBS (Open Broadcaster Software) por Miguel Alonso. Estas experiências compartilham o mundo íntimo de cada um dos integrantes e na composição de mundos criam-se outras sensações da realidade. Como aponta Fattorelli:

As tecnologias digitais instauram uma nova noção de realidade, e não o fim do real. Uma realidade fragmentada, construída, dependente das interfaces e subordinada aos procedimentos de modelização e de simulação, produto e efeito de novas partilhas entre o ver e o saber, entre o visível e o invisível. (2013, p. 101)

Fig 1. Registro de performance online Janelas Afetivas, realizada em 21 de outubro de 2020 - Hub Eventos, Media Lab. | Fonte: COM.6, 2020.

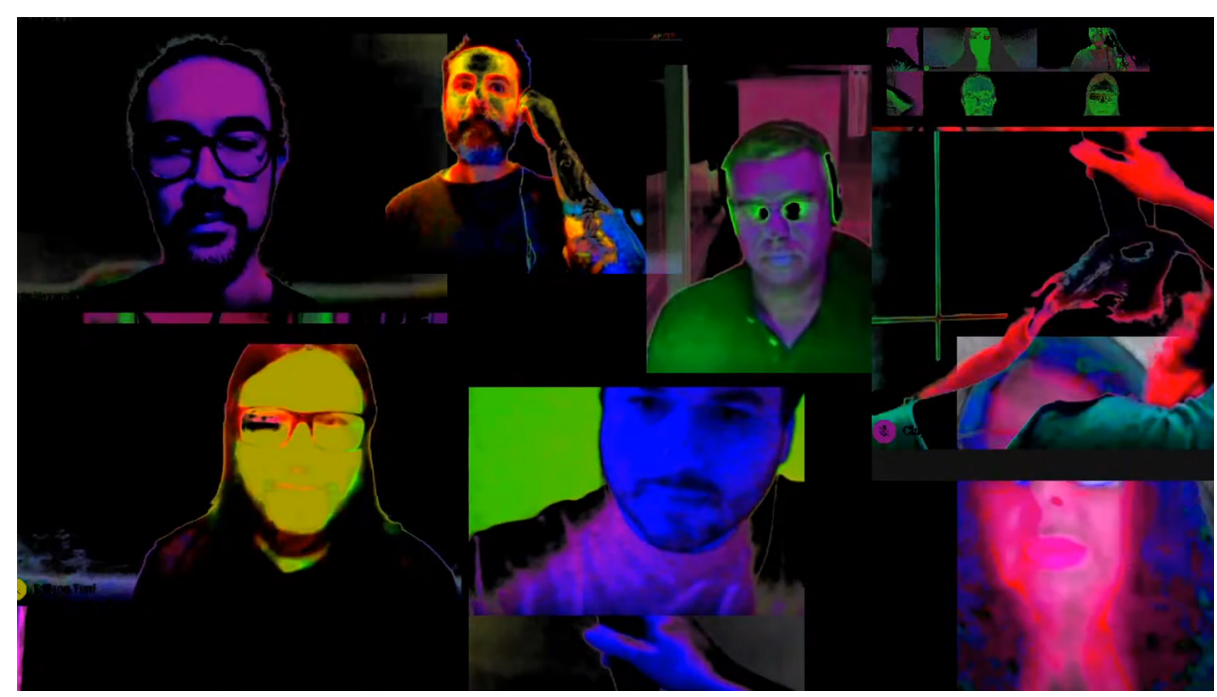


Ao mesmo tempo em que abrimos nossas intimidades, também somos invadidos por uma imensa quantidade de informações. Estar conectados nos traz a sensação de responsabilidade para resolver todas as demandas e cobranças de ações e resultados. Estas por sua vez rompem as fronteiras físicas, portanto somos a todo instante expostos aos acontecimentos do mundo. Não só compartilhamos e recebemos as intimidades alheias, mas também compartilhamos subjetividades. É importante ressaltar que as discussões foram provocadas inicialmente por Bachelard (2008) e misturadas com as vivências e referências de cada artista. Desta forma, o comportamento performático e a representação do espaço configuram o canto do mundo dos participantes da proposta.

\footnotetext{
Como é que aposentos secretos, aposentos desaparecidos, transformam-se em moradas para um passado inolvidável? A casa nos fornecerá simultaneamente imagens dispersas e um corpo de imagens, em ambos os casos provaremos que a imaginação aumenta os valores da realidade (Bachelard, 2008, p. 23).
}

O espaço habitado, quando compartilhado, é outro e está além da realidade ao misturar-se com outros mundos no imaginário. Este espaço está contaminado pelo mundo, mas ainda é o nosso universo. A casa ainda é o abrigo, mas agora, em alguns momentos, compartilhamos vestígios deste lugar. O lar se torna caminho deste fluxo de trocas entre os elementos internos e externos ao corpo, que outrora habitavam outros lugares que não necessariamente faziam parte do ambiente residencial. Agora, elementos cotidianos da casa e da vida doméstica também dialogam. Estes movimentos são intermediados pelos componentes eletrônicos, que ganham no ambiente residencial os papéis desempenhados anteriormente nos âmbitos profissional, acadêmico, social, suprindo também as limitações de deslocamento.

O tempo é impreciso em uma proposta como Janelas Afetivas. $O$ tempo da ação não é o mesmo da recepção, pois é o tempo contaminado das transmissões, das compressões, perdas e falhas da movimentação de dados, das limitações de processadores e memórias. É preciso lidar com as assincronias que encurtam e dilatam as narrativas: cada membro provoca e espera, escuta, vê, imagina, e finalmente reage às ações dos outros. Tal mistura performática gera derivações de nós mesmos em ressonância ao tempo dos outros e das máquinas.

Uma vez amalgamados pelos diálogos não-verbais e intimidades compartilhadas, o eco imagético dos encontros proporciona a diluição das janelas conformadas em videoconferência. Através de distorções de cores, 
recortes e sobreposições, criam-se colagens audiovisuais que permitem combinações ativas e fusões entre os vídeos transmitidos pelos artistas, de forma a romper com a estética estéril das plataformas de reuniões, subvertendo algumas das convenções que se estabeleceram para os encontros remotos desse período pandêmico.

Enquanto proposição poética, Janelas Afetivas não se encerra como uma obra em si, mas desdobra-se em uma série de apresentações ${ }^{1}$. A cada apresentação, um experimento se instala na rede, um trânsito entre as camadas dos ambientes remotos que se expandem em devaneios e resultam em intersubjetividades.

\section{Considerações Finais}

A exacerbação de gestos cotidianos e íntimos frente às webcams incita a recuperação de debates acerca do processo de revisão dos espaços privativos como locais de refúgio. A contínua cobrança de ações e resultados, à qual somos submetidos quando conectados à rede, não permite que sejam mantidas fronteiras rígidas entre as dimensões público/privado da realidade, enquanto o excesso de "janelas" e conexões podem gerar angústia e cansaço. A disrupção entre espaços públicos e privados, explorada nos experimentos precursores da videoperformance e nos trabalhos de Sadie Benning, Claudio Bueno, Eva e Franco Mattes, é elevada à potência diante das ferramentas disponíveis e da vivência compartilhada, em uma situação de exceção, que padroniza a rotina de uma parcela considerável da população mundial. Enquanto a abertura dos espaços privativos dos artistas pioneiros da performance se dá de uma maneira sutil, que não aprofunda o debate sobre o tema, a indiscrição da câmera nos demais trabalhos anteriormente mencionados trazem a angústia e as dúvidas de uma adolescente, o fetiche de invadir a intimidade do artista e as diferentes reações diante de um terror encenado, que oscilam do desespero ao sarcasmo. Em diferentes graus é exposta uma hostilidade inerente às performatividades exibicionistas e voyeuristas que hoje habitam as redes. A proposta de Janelas Afetivas é avessa a essa hostilidade, agora manifestada na dureza e antipatia que as plataformas de videoconferência ocasionam. A cada apresentação é instaurado um novo evento, uma celebração desconexa que pode ser vista como uma certa ludicidade socioemocional diante o atual cenário.

Janelas Afetivas ocorre diante de um momento de exaustão pelo uso de tecnologias de comunicação síncrona e remota, um cenário cuja dinâmica envolve o ligar e desligar de câmeras e microfones a todo momento, bem como lidar com as preocupações e situações domésticas, que agora estão misturadas às formalidades profissionais, ocasionando confusões na percepção de tempo e espaço. Em situação de isolamento, a casa se transmuta em confinamento, e os softwares de videoconferência acabam se tornando uma das poucas alternativas de experiência social, a maioria das quais são 
inevitáveis por motivos de trabalho, estudo ou resolução de burocracias do cotidiano. $\mathrm{O}$ esgotamento se amplifica pela rigidez e frieza de janelas digitais brilhantes que compartimentam existências enquanto ressecam nossas visões e pontos de vista. A eterna negociação social entre o que se é, o que se quer ser e o que se aparenta ser se dilui: não há como sustentar tais diferenças nesse emaranhamento entre público e privado que altera o mundo íntimo e, muitas vezes, interfere no corpo físico.

Mas nos resta o afeto, o querer estar e criar juntos. As mesmas tecnologias que nos cansam permitem outros modos de afetividade e criatividade. $O$ afeto supera a burocracia, o comum, nos distancia das monotonias cotidianas, faz com que vontades sejam externalizadas e que o privado e íntimo se tornem públicos como um discurso político, pois afetamos os outros e somos afetados. Janelas Afetivas assume os julgamentos e riscos de tais situações, mas os subverte em forma de proposição poética compartilhada. São alternativas para se viver o "novo normal".

1 Nos dias 17 e 24 de setembro de 2020, às 14h, a ação foi transmitida no evento Zonas de Compensação 7.0, organizado pelo GIIP, Grupo Internacional e Interinstitucional de Pesquisa em Convergências em Artes, Ciências e Tecnologias. (Instituto de Artes da Unesp, Campus São Paulo, SP). (https://youtu.be/RW4cnN7pLyQ?t=1627. Acesso em 26/10/2020). No dia 21 de outubro de 2020, às 20h, Janelas Afetivas é realizada e exibida como parte da programação de performances da exposição EmMeio\#12, no Hub de eventos organizado pelo Media Lab UFG, PUC-SP e Universidade Anhembi Morumbi. A ação na mostra EmMeio\#12 contou com a participação do professor Dr. Cleomar Rocha. (https://youtu.be/ sbF6BUwCzA4. Acesso em 26/10/2020) 


\section{Referências}

BACHELARD, Gaston. A poética do espaço. São Paulo: Martins Fontes, 2008.

BASTOS, Marcus V. F. Através da janela: vídeo online em dias de tempos e espaços desarticulados. In Grupo de Estudos Humanidades Computacionais. Instituto de Estudos Avançados da Universidade de São Paulo. 2020. Disponível em: <http://www.iea.usp.br/publicacoes/ensaios/atraves-da-janela-video-online-em-dias-de-tempos-e-espacos-desarticulados>. Acesso em 26 outubro 2020.

BEIGUELMAN, Giselle. Admirável mundo cíbrido. 2004. Disponível em: <https://www.academia.edu/3003787/Admir\%C3\%A1vel_mundo_c\%C3\%ADbrido> Acesso em 26 outubro 2020. BUENO, Claudio. Casa Aberta. 2010. Disponível em <http://buenozdiaz.net/index.php/project/casa-aberta/>. Acesso em 26 outubro 2020.

COM.6. Janelas Afetivas (Hub Eventos 2020). 2020. Disponível em https://youtu.be/sbF6BUwCzA4. Acesso em 26 outubro 2020.

DI FELICE, Massimo. Paisagens pós-urbanas: o fim da experiência urbana e as formas comunicativas de habitar. São Paulo: Annablume, 2009.

FATORELLI, Antonio. Fotografia contemporânea: entre o cinema, o vídeo e as novas mídias. Rio de Janeiro: Senac Nacional, 2013.

FONTCUBERTA, Joan. A câmera de pandora: A fotografi@ depois da fotografia. São Paulo: Ed. G. Gilli, 2012.

LEMOS, André. Cultura da mobilidade. In: BEIGUELMAN, G.; LA FERLA, J. (org.) Nomadismos tecnológicos. São Paulo: Editora Senac, 2011.

MELLO, Christine. Demasiada Presença. Texto curatorial para a exposição realizada na Escola São Paulo. 2009.

PARENTE, André. Alô, é a Letícia? In Revista Performatus, ed. 08, ano 2. 2014. Disponível em: <https://performatus.com.br/estudos/leticia-parente/>. Acesso em 26 outubro 2020.

POLICARPO, Clayton. Breve genealogia do retrato queer/cuir. In Vulgar. São Paulo: Ed. Do Autor, 2020.

PWC Brasil. Relatório Anual PricewaterhouseCoopers Brasil 2020. 2020. Disponível em <https://www.pwc.com.br/pt/publicacoes/assets/2020/relatorio_anual_20.pdf>. Acesso em 30 outubro 2020.

SALTER, Chris. Entangled: Technology and the transformation of performance. Cambridge: MIT Press, 2010.

SANTAELLA, Lucia. A ecologia pluralista da comunicação. São Paulo: Paulus, 2010. 